disorder in the digestive organs, and sometimes a sweet taste in the throat; these symptoms may go on ten or twenty years before they end in the acute or chronic form of the disease, when the leaden tinge in the gums will be found, proving the system to be now saturated with lead; and if the disease assume a chronic character, the symptoms will be somerhat similar to the acute, in a milder degree-namcly, constipation of the bowels, sometines diarrhoe ; a coppery taste; tongue covered with a dark cream-colonred mucus; a griping pain in the bowels many hours during the day and night, ofteir around the umbilicus, extending over many parts of the abdominal region; loss of appetite, nansea and sometimes vomiting; of ten an exceedingly sweet taste in the throat and faucrs; great depression in the nervous and muscular system; seldon excitement in the vascular system; pulse generally slow and feeblo; the skin dry, and all the sucretions diminished; kidneys torpid; urine scanty, and of a dark colour.

Treatment.-Mild purgatives daily, or every other day; calomel and opium every six or eight hours; then indide of potass in one or two grain doses. If the pain is frecuent and distressing, occasional doses of laudanum. Diarrhoa is sometimes kept up by scybala or vitiated secretions, and may require castor-oil, previons to the nse of astringents. Whe diet should be light and nutritious; dilute freely with mucilaginous drinks. When pain is unusually severe, the warm-bath has a striking effect; bran ponltices and hot salt are always nseful, and may be applied to any of the affected rarts.

When patients have premonitory symptoms, they shonld be removed from their cmployment, the sin frequently washed, and the clothing chenged, with proper remedies; by these precautions, many serious attacks may probably be prevented. The sweet taste from the throat may be removed by frequent gargling with water, or water mixed with iodide of potass

Those who are predisposed to the disease may take iodide of potass once or tivice every year; "and as a preventive take sulphuric acid lemonade." $*$ The patients should always wear warm clothing.

Chloroform has lately been used by the French. The usnal practice of Dr. Aran is, to apply a compress dipped in chloro. form to the abdomen for the space of twenty minutes, and at the same time to give internally about thirty drons in mueilage. These doses are repeated according to circumstances. He has treated eight cases in this manner, all of which recovered in from two to six days, (see Provincial Journal for March, 1851.) I think chloroform may probably be used with advantage, and may diminish pain in the acute species, and be useful in the chronic form, and I have no doubt many of the suffering patients will willingly submit to its use in any way.

- $\mathbf{H}-$, aged forty, has been employed as a gliss-cutter the last twenty years; for six weeks has complained of frequent severe griping pain in the bowels, not increased by pressure, with pain in the lower part of the loins, and in most of the muscles of the extremities, with many of the other symptoms before detailed, but not constipation. With these symptoms in a slighter degree he partially followed his occupation several weeks, till he was so worn down by suffering and debility that he was unable to leave the house, and seat for me. I now for the first time examined his gums, and the blue tinge at once pointed out the nature of his complaint. He was soon convalescent by the usual remedies. The pains left the extremities and settled in the abdominal and pectoral muscles.

- C- aged thirty-five, a painter for twenty years, has lately suffered severely, and with the usual symptoms, with blue gums; he also had diarrhoa, vomiting, and strangury, several weeks before he applied to me. Both these patients had two severe attacks within a period of fourteen months, and $\mathrm{C}-$, had an attack of gout in both feet during convalescence.

To show the direct influence lead has on the muscular system, we often see paralysis of the right arm in painters, and more particularly in the adductor pollicis in glaziers, whose frequent occupation is to spread the "putty" with the thumb, to fasten panes of glass in the windows; and putty is a composition of lead.

In the acnte form of the disease I have frequently seen numerous successive paroxysms for months, and I have witnessed a succession of attaclss in the chronic species.

Persons will sometimes be employed in lead manufactories ten or twenty years, and remain free from violent suffering, but rarely free from slight symptoms; and when severe attacks have once occurred, without great care patients may be martyrs to the disease, which may eventually destroy life.
The gums of those patients employed in lead should occasionally be examined, and when they assume a slight blue tinge, proper remedies and precautions should be adopted for I consider no patient safe till the gums wear a healthy colour, and patients will be doomed to fresh and perhaps more severe altacks. The long-continued suffering produces such a depression in the nervous system, that some of the patients appear willing to destroy themselves; and in the latter stages,

"Yellow sickness sits cavern'd in the hollow eye."

I have had an opportunity of rare occurrence of witnessing the deloterious effects ot lead on the human frame, in consequence of a miller's servant, by mistake, mixing thirty pounds of acetate of lead with about eighty sacks of flour, already detailed by me in the Provincial Journal published in June, 1849, nnd in THe Lances for August, 1849; and as the acute or chronic form of the disease mas witnessed by me daily for many months, it induced me to investionte the disease, and to drew the foregoing deductions and conclusions; and I trust and hope that toxicologicts will carry on the inquiry, as the health of thousands may be benefited.

Dr. Watson, in his very valuable lectures, states that Mr. Tones, a dentist, has come to the conclusion that the blue tinge in the gums is produced by some chemical action between the tartar that forns on the teeth where they meet the gums, and the lead which pervades the system; but when the system is saturated with liad, I feel convinced the blue tinge will oconr where no tartar exists; for I lave frequently seen it in young persons, aid also in childreie.

Stourbridge, Worcestershire, 18 šl.

\section{A CASE OF INSANITY CURED BY A SURGICAL OPERATION.}

Br WILLIAM BAYARD, M.D., \&c., St. John's, New Brunswick.

RoRERT T-, of Conchiboguac, in New Brunswick, twentythree years of age, was placed in the Provincial Lunatic Asylum, having suffered for some time under mental derangement. His father stated, in reply to interrogatories, that his right eye was injured at the time of his birth-as he thought, by the midwife-it being much swollen and inflamed, in which state it continued for three months, when it became better, though permanently enlarged; that, about four years ago, the same eye was injured by a blow from a chip, when cutting wood; that the eyelid was cut, but he cannot say whether the eyeball was punctured. There was an occasional discharge from it till about six months prior to the operation, when it ceased, and was followed by an increase in its size, accompanied with frequent pain in the head. His intellect was unimpaired till this period, when he manifested unequivocal symptoms of insanity, and, preferring his bed, he continued in it constantly.

He remained in the lunatic asylum, under the charge of Dr. Waddle, the medical superintendent, for two months, withont experiencing any improvement in his symptoms, when my father, Dr. R. Bayard, and myself, were called upon to visit him: we did so, and found him in bed, muttering a few words in a low and mournful tone of voice. He seemed totally regardless of surrounding objects; there was an expres. sion of pain in his countenance, and he was disinclined to any lind of exertion, though his manner and temper were gentle; he suffered from great want of sleep; the eyeball was enlarged to about the size of a small orange, protruding beyond the orbit, and much disorganized; there was no appearance of pupil or iris, and the eyelids adhered throughout their entire surface to the selerotic membrane. The increased size of the eye was evidently owing to an increased quantity of fluid within its coats, and it was very firm and hard.

The general health of the patient was declining, characterized by loss of flesh and strength, impaired sleep, and constipation of bowels. He took food apparently more as an act of obedience than from any appetite for it. He preferred his bed, but when taken from it his movements were unsteady from debility. The history, progress, and symptoms of the disease of the eye, and the subsequent insanity, induced us to believe that an operation offered the only prospect of relief. The case, with its uncertainties and possibility o: relief, was represented to his father, who imme. diately assented to the performance of the operation; and accordingly, on the $22 n d$ of May, 1850, he was removed from the asylum to St. John's. Previous to operating, the patient was subjected to the iufuence of chloroform, which, although freely exhibited, occasioned only slight ex- 
citement, and a disposition to sing the words he generally muttered. I removed the eye in the presence of Dr. Bayard, Dr. Livingstone, and several other medical gentlemen.

The patient allowed himself to be placed upon the table, and his hands secured, without offering the slightest resistance. He was perfectly passive, and I do not think he would have moved or given trouble, if no precaution had been observed. The operation was performed in the usual manner. The hæmorrhage (as is usual in such cases) was profuse; but it was easily restrained by plugging the orbit with lint moistened with cold water, over which a gentle compress and cold water dressing was applied, and the patient was put into bed. During the operation he manifested no increased feeling of suffering, and continued muttering as before.

The membranes of the enlarged eye contained nothing but a glairy fluid resembling the white of an egg; and at the base of the tumour, external to its membranous covering, and attached to the optic nerve, at its exit through the foramen, there was a small sac, containing a calculous concretion, in size equal to a large pea, rendering it necessary to divide the nerve close to the bone. The sac containing the calculus was entire, and easily separated from the nerve. The wound healed favourably, and at the end of a fortnight the patient returned home with his father, travelling upwards of 150 miles without experiencing suffering or inconvenience. His health gradually improved, attended with the restoration of his mental faculties.

Mr. T- made the following statement to the Rev. $R$. Irvine, who kindly attended him during his illness, and saw him at Conchiboguac after his recovery. I publish it, as it affords interesting matter for the physiologist: and as we have much to learn respecting that morbid condition of the brain which constitutes insanity, every fact indicative of cerebral suffering and mental action may direct attention to some important inquiry. He stated " that he had no recollection of any person or thing for three weeks before he left his home; that period being, as he termed it, a blank in his existence. A few miles from his residence, on his way to St. John's, his attention was suddenly arrested by a spring on the road-side, with which he was familiar, and from that moment until the present he recollects the most minute incident that came under his notice;" particularly several occurrences in the Junatic asylum, his journey to St. John's, his admission into the asylum, the conduct of some of the lunatics, his removal from the asylum for the operation, and the appearance of the gentlemen who surrounded him. During his lunacy, he imagined that the bodies of all he saw were spirits clothed in blood-red garments; all objects presented a scarlet appearance to his left eve; the right one possessed no power of vision. On recovering, he commenced communication with his family by writing on the wall and on a slate, as he experienced great difficulty in articulating words. During his illness he felt inclined to talk, but could only express a few words, which were made in reply to some of his friends, who (when he first manifested incoherence) told him of it, when he said, "Oh no, I did not say that, did I ?" which words he constantly repeated during his illness.

Mr.T- continues to enjoy perfect health of body and mind, and has never complained of pain or uneasiness in the orbit from which the eye was removed, and it is now upwards of a year since the operation was performed.

St. John's, New Brunswick, 1851.

\section{OBSERVATIONS ON THE SOUNDS OF THE HEART.}

By RICHARD BROWN, EsQ., M.R.C.S., L.A.C., \&c., Cobham.

FEw subjects, perhaps, have claimed more attention from physiologists than the one upon which $I$ am about to offer some remarks, and I may add, none in which a greater discrepancy of opinion has been manifested.

Harvey and Haller describe the contraction of the auricles as preceding those of the ventricles. Laennec conceived that the contraction of the auricles followed those of the ventricles. Turner, Corrigan, Williams, Hope, and Bouillaud, have shown the inaccuracy of Laennec's opinion. Dr. Williams investigated this subject, and his inferences were confirmed by the Committees of the British Association-namely, that the contraction of the ventricles followed immediately that of the auricles.

The first sound of the heart was ascribed by Mr. Carlisle to the rush of blood into the great arteries; by Mons. Rouanet and others to the closing of the auriculo-ventricular valves; by Dr. Hope, to the collision of the particles of fluid in the ventricles; and by Dr. Williams, to the muscular contraction of the heart itself.

The second sound was ascribed by Dr. Hope to the impulse of the blood from the auricles filling the ventricles; by Messrs. Carlile, Carswell, Rouanet, Bouillaud, and others, to the suction of the ventricles, causing the elevation of the sigmoid valves, and to the reaction of the arterial columns of blood against these valves.

The experiments performed by Dr. Williams, assisted by Dr. Hope and others, in order to determine these points, proved that the first sound is produced by the muscular contraction of the ventricles, and that the second sound is caused by the reaction of the arterial columns of blood, tightening the semilunar valves at the diastole of the ventricles.

The first motion of the heart following the interval of repose is the systole of the auricle, which I consider accompanies the diastole of the ventricle; and the systole of the ventricle imme diately follows its diastole, commences suddenly, and considerably diminishes the volume of the organ.

On applying the ear or a stethoscope over the præcordial region, two sounds are heard following each other; the first is dull and prolonged, whilst the second is shorter and sharper. The first sound is produced during the diastole, and the second during the systole of the ventricles; and in support of this theory I will briefly state the circumstances under which this opinion was formed.

Some few weeks since, attending a patient labouring under increased action of the heart, and whilst conducting an examination, I could distinctly appreciate the inward current of blood from the auricle to the ventricle, producing the first sound by suddenly distending this latter cavity. The apex of the heart striking against the walls of the chest in the neighbourhood of the fifth and sixth ribs, communicated to the ear at this moment a shock (the heart's impulse). Immediately followed the second sound, produced by the onward current of blood through the aortic opening, propelled by the contrac tion of the ventricles. I observed, moreover, that the first sound did not exceed the space in which the impulse was felt, but that the second sound was audible in nearly the whole extent of the chest, which would tend to strengthen the theory I have advanced, inasmuch as the sound produced by the diastole of the ventricle would be circumscribed, whereas that produced by the systole would be diffused.

Whilst my attention was directed to this subject, a case came under my notice in which a bruit de râpe was distinctly heard in the second sound of the heart, and over a considerable portion of the chest.

I diagnosed ossification of the aortic semilunar valves and arch of the aorta, believing that during the production of the second sound (systole) the current of blood was passing in this direction. The patient died shortly afterwards, and a post. mortem examination of the body disclosed the correctness of my opinion.

Cobham, 1851.

Annual Public Meeting of the Academy of Medicine of Parrs.-The Academy held its annual meeting on December the 16th, 1851. A general report was read as usual on the prizes awarded by the Academy in 1851. The subjects of the prizes for 1852 and 1853 , were then made known, and M. Dubois (d'Amiens) read a panegyric discourse on Hallé. 'The prize of the Academy on White Swelling was awarded to Mr. Richet, well known for his successful labours on the subject. Madame de Civrieux's prize on Convulsions was not awarded to any of the competitors. A prize on Melancholia only produced an encouragement. Among the subjects for 1853, we notice the following:- "Is there any Paraplegia independent of Myelitis?" The subject of Portal's prize is, "The Anatomy and Physiology of the varions kinds of Goître." Madame de Civrieux's, "The History of Tetanus." Dr. Capuron's, "On the Physiological and Pathological Circumstances of the Puerperal State." The Argenteuil prize, on "The Therapeutics of Stricture," has now accnmulated to $480 \%$; it is an hexennial prize, and was not awarded from 1838 to 1844 . The Academy prize for 1852 is, "On Ergot of Rye as regards Physiology, Midwifery, and Hygiene." Portal's, for 1852, "On the Pathological Anatomy of the Inflammation of Bone;" and Madame de Civrieux's, for the same year, "The Etiology of Epilepsy: inquire for the indications which the study of its causes may furnish in regard to the preventive or curative treatment of the disease." 